\title{
Guideline development for the management of gout: role of combination therapy with a focus on lesinurad
}

This article was published in the following Dove Press journal:

Drug Design, Development and Therapy

24 October 2017

Number of times this article has been viewed

\section{Graeme Jones' \\ Elena Panova' \\ Richard Day ${ }^{2}$}

'Menzies Institute for Medical Research, University of Tasmania, Hobart, TAS, Australia; ${ }^{2}$ University of New South Wales, Medicine, St Vincent's Hospital, Sydney, NSW, Australia
Correspondence: Graeme Jones

Menzies Institute for Medical Research, University of Tasmania, Private Bag 23,

Hobart, TAS, Australia

Tel +6I 362267700

Email g.jones@utas.edu.au

\begin{abstract}
The aim of this review was to summarize the evidence for combination therapy to achieve serum urate (SUA) target levels in gout. Within this overarching aim, a second aim was to evaluate the evidence for a new uricosuric agent lesinurad, which inhibits urate transport in the kidney. In summary, this review indicates that there are a number of ways to approach patients who do not achieve a target serum urate with allopurinol (APL) monotherapy. These include higher doses of APL up to $600-800 \mathrm{mg} / \mathrm{d}$, switching to febuxostat, or adding in a uricosuric. For the latter option, controlled supporting evidence is available for benzbromarone, probenecid, and lesinurad. All options appear similar in terms of success rates, so the choice of option comes down to physician and patient choice, cost, experience, and strength of the evidence base. Increasing the dose of APL is the cheapest option, while febuxostat is consistently superior to standard doses of APL. The strongest evidence for the uricosuric option is available for lesinurad as trials of other agents are either nonexistent or based on small single-centre trials. It is suggested that guidelines should be expanded to consider all of these evidence-based options in the not-uncommon occurrence of APL inadequate response.
\end{abstract}

Keywords: gout, therapy, combination, urate lowering

\section{Introduction}

Gout is the most common cause of inflammatory arthritis, especially in Western countries, and its prevalence is increasing. ${ }^{1}$ This is despite the long-term availability of effective therapies and largely consistent management guidelines. Gout results from sustained high levels of uric acid leading to crystal deposition and acute arthritis in genetically susceptible people. Outcomes of this include tophi, chronic arthritis, kidney stones and renal impairment, as well as, most commonly, recurrent acute arthritis. Gout is also frequently associated with comorbidities such as metabolic syndrome and cardiovascular disease as well as premature mortality. Risk factors for hyperuricemia and gout are well understood and include age, male gender, alcohol consumption, postmenopausal status in females, renal impairment, diuretic therapy, and genetic control of urate transport, ${ }^{2}$ as well as a number of drugs.

Reasons for why gout is poorly controlled include poor compliance with potentially curative medication, especially by males, and suboptimal use of existing therapies. $^{3}$ In the last decade, more options have become available, and this has resulted in a plethora of new guidelines. ${ }^{1,45}$ The aim of this review is to describe the role of combination therapy in gout, with a focus on a new therapeutic agent named lesinurad (LESU). 
In general, there is consensus that the target urate level is $6 \mathrm{mg} / \mathrm{dL}$ or less for acute gout and $5 \mathrm{mg} / \mathrm{dL}$ or less for chronic or tophaceous gout. ${ }^{1,4,5}$ Most guidelines focus on lifestyle modification and monotherapy with allopurinol (APL) or febuxostat (FBX) as standard of care. All the recent guidelines make a comment about combination therapy (Table 1). The American College of Rheumatology and British Society of Rheumatology guidelines say that combination therapy is indicated if serum urate (SUA) target has not been met by appropriate or optimal dosing of a xanthine oxidase inhibitor. In comparison, the European League against Rheumatism states that uricosuric monotherapy, FBX monotherapy, or combination therapy are all reasonable options if APL monotherapy fails. The guidelines are relatively silent on what is an optimal dose of APL monotherapy. Renal function and, potentially, urinary urate excretion should be assessed prior to starting therapy. Most clinicians use a dose of up to $300 \mathrm{mg} / \mathrm{d}$ with a dose adjustment for renal impairment, and they are reticent about higher dose rates. Emerging evidence suggests this caution is not warranted. ${ }^{6}$ Table 2 shows success rates for various approaches to gout therapy. There are few headto-head studies but these studies do have similar inclusion criteria. It is apparent that the usual dose of APL is not that successful even in the setting of controlled trials, with only $30 \%-70 \%$ achieving target SUA. ${ }^{4}$ In a real-world setting, this is likely to be worse given the poor compliance with therapy. ${ }^{3}$ If one pushes the APL dose to $600 \mathrm{mg} / \mathrm{d}$, then success rates are considerably better, with $69 \%-78 \%$ achieving a target SUA. ${ }^{6,7}$ Some rheumatologists use even higher doses up to $1,200 \mathrm{mg} / \mathrm{d}$, but there is no published evidence to support this practice. APL is cheap and has a well-known safety profile. Serious side effects are rare but include hypersensitivity

Table I Current guideline recommendations for the use of combination urate-lowering therapy

\begin{tabular}{lll}
\hline Organization & Year & Recommendation \\
\hline ACR $^{4}$ & 2012 & $\begin{array}{l}\text { Combination oral urate-lowering therapy with } \\
\text { xanthine oxidase inhibitor agent and uricosuric } \\
\text { agent is appropriate when the serum urate } \\
\text { target has not been met by appropriate dosing } \\
\text { of a xanthine oxidase inhibitor. } \\
\text { If the serum urate target cannot be reached } \\
\text { by an appropriate dose of APL, APL should be } \\
\text { switched to FBX or a uricosuric or combined } \\
\text { with a uricosuric. } \\
\text { BSR' }\end{array}$ \\
2017 & $\begin{array}{l}\text { A uricosuric agent can be used in combination } \\
\text { with a xanthine oxidase inhibitor in patients } \\
\text { who do not achieve a therapeutic serum urate } \\
\text { target with optimal doses of monotherapy. }\end{array}$ \\
\hline
\end{tabular}

Abbreviations: ACR, American College of Rheumatology; APL, allopurinol; BSR, British Society of Rheumatology; EULAR, European League against Rheumatism; FBX, feboxustat. syndromes such as Stevens-Johnson Syndrome and toxic epidermal necrolysis. These may be more common in those with renal impairment, short duration of therapy, concomitant diuretic use, and HLA-B*5801 type. ${ }^{8}$ In our opinion, increasing the dose seems a very logical step if target SUA is not achieved. There is good evidence that the dose of APL needed to achieve target concentrations of urate is a function of the baseline serum urate concentration, with higher concentrations needing higher doses. ${ }^{9}$

FBX is another xanthine oxidase inhibitor. In both indirect and direct comparisons, it appears considerably more effective than APL at achieving a target SUA, especially at $80 \mathrm{mg} / \mathrm{d},{ }^{10}$ indicating it provides stronger blockade of xanthine oxidase (Table 2). In a number of jurisdictions, it can be used first line, but in some countries such as Australia it is only approved for those who fail APL either for efficacy or toxicity (due to its higher cost).

\section{Uricosurics}

There are a number of uricosuric agents which increase uric acid excretion in the urine. These include sulfinpyrazone, probenecid, benzbromarone, fenofibrate, losartan, and highdose aspirin.

These agents are not available in all jurisdictions, eg, Australia only has probenecid. In clinical practice, they are most commonly used in combination. Data for existing medications is summarized in Table 2. There is very limited

Table 2 Proportion achieving a target urate level by treatment type

\begin{tabular}{|c|c|}
\hline Urate-lowering therapy & $\begin{array}{l}\% \text { achieving target level } \\
\text { ( }<5 \text { mg/dL unless stated) }\end{array}$ \\
\hline APL monotherapy (various studies) & $30 \%-70 \%$ a,4 \\
\hline High-dose APL (up to $600 \mathrm{mg}$ ) & $78 \%,^{7} 69 \%^{6}$ \\
\hline \multirow[t]{3}{*}{ Feboxustat versus $\mathrm{APL}^{\mathrm{a}, 9}$} & APL $300 \mathrm{mg} 40 \%$ \\
\hline & FBX $40 \mathrm{mg} 49 \%$ \\
\hline & $\mathrm{FBX} 80 \mathrm{mg} 70 \%$ \\
\hline \multirow[t]{2}{*}{ APL plus benzbromarone $v \mathrm{APL}^{\mathrm{a}, 9}$} & APL $60 \%$ \\
\hline & Combination $74 \%$ \\
\hline APL plus probenecid & $65 \%^{10}$ \\
\hline \multicolumn{2}{|l|}{ APL \pm LESU } \\
\hline APL alone & $28 \%^{12}$ \\
\hline APL plus LESU 200 mg & $63 \%^{\mathrm{a}, 11}, 54 \%^{12}$ \\
\hline APL plus LESU 400 mg & $78 \%^{\mathrm{a}, 11}, 59 \%^{12}$ \\
\hline \multicolumn{2}{|l|}{ Feboxustat \pm LESU } \\
\hline \multirow[t]{3}{*}{ Feboxustat monotherapy } & $67 \% 80 \mathrm{mg}^{\mathrm{a}, 13}$ \\
\hline & $56 \% 40 \mathrm{mg}^{\mathrm{a}, 13}$ \\
\hline & $47 \% 80 \mathrm{mg}^{14}$ \\
\hline Feboxustat plus LESU 200 mg & $56 \%^{14}$ \\
\hline Feboxustat plus LESU $400 \mathrm{mg}$ & $100 \%{ }^{\mathrm{a}, 13}, 76 \%^{14}$ \\
\hline
\end{tabular}

Note: ${ }^{\mathrm{a}}<6 \mathrm{mg} / \mathrm{dL}$.

Abbreviations: APL, allopurinol; LESU, lesinurad; FBX, feboxustat. 
controlled data. Both benzbromarone ${ }^{10}$ and probenecid ${ }^{11}$ in combination are more effective than APL monotherapy based on three small trials. No controlled data is available on the other agents.

\section{LESU}

LESU is a new selective uric acid reabsorption inhibitor that has recently been given US Food and Drug Administration and European Medicines Agency approval and marketing authorization. While mentioned in the British Society of Rheumatology guidelines, no recommendations for its use were given. This review will summarize the four key clinical trials. ${ }^{12-15}$ Table 2 provides the summary efficacy data for comparison purposes. Table 3 provides safety data.

\section{APL in combination with LESU}

The initial Phase II trial ${ }^{12}$ evaluated the efficacy and tolerability of LESU in combination with APL versus APL monotherapy in patients with active gout and an inadequate response to APL (defined as an SUA consistently $\geq 6 \mathrm{mg} / \mathrm{d}$ ). The patients were randomized 2:1 to 4 weeks of double-blind treatment with LESU (200, 400 or $600 \mathrm{mg} / \mathrm{d})$ or matching placebo (PBO) in combination with their APL dose at study entry (200-600 mg/d). Colchicine prophylaxis for gout flares was given to all patients. The primary endpoint was change in SUA levels at 4 weeks. A pharmacokinetic substudy was also conducted. Safety was assessed throughout. Patients ( $n=208$ ) received $\geq 1$ dose of blinded medication. LESU 200, 400 , and $600 \mathrm{mg}$ in combination with APL produced significant mean percent reductions from baseline SUA of $16 \%$, $22 \%$, and $30 \%$, respectively, versus a mean $3 \%$ increase with PBO $(p<0.0001$, all doses versus PBO). Similar results were observed in patients with an estimated creatinine clearance down to $30 \mathrm{~mL} / \mathrm{min}$. The incidence of adverse events was $46 \%, 48 \%$, and 54\% with LESU 200, 400, and $600 \mathrm{mg}$, respectively, and $46 \%$ with $\mathrm{PBO}$, with no deaths or serious adverse events. The authors concluded that LESU achieves important reductions in SUA in combination with APL in patients who warrant additional therapy on APL alone.

The CLEAR 1 study was a 12-month, multicenter, randomized, double-blind, $\mathrm{PBO}-$ controlled Phase III trial ${ }^{13}$ conducted to evaluate daily LESU (200 mg or $400 \mathrm{mg}$ orally) added to APL versus PBO plus APL in patients with SUA levels above $6.5 \mathrm{mg} / \mathrm{dL}$ and in whom active gout during the previous year was studied. The primary endpoint was the percentage of patients achieving an SUA $<6.0 \mathrm{mg} / \mathrm{dL}$ at month 6. Key secondary endpoints were the mean gout flare rate requiring treatment (months 7-12) and the proportions of patients with complete resolution of at least 1 target tophus (month 12). The study patients $(n=603)$ were predominantly male with a mean age of 51.9 years, gout duration of 11.8 years, and baseline SUA level of $6.94 \mathrm{mg} / \mathrm{dL}$, and they were receiving an APL dosage of just over $300 \mathrm{mg} / \mathrm{d}$. LESU at doses of $200 \mathrm{mg}$ or $400 \mathrm{mg}$ added to APL therapy significantly increased the proportions of patients who achieved SUA target levels by month 6 as compared with those receiving APL monotherapy (54.2\%, 59.2\%, and $27.9 \%$, respectively, $p<0.0001)$. LESU was not significantly superior to APL alone for rates of gout flares and resolution of tophi. LESU was generally well tolerated except for higher rates of predominantly reversible renal impairment (Table 3). The most common adverse events were upper respiratory tract infections, sinusitis, increased blood creatinine levels, and headache. Serious adverse events apart from renal complications included cerebrovascular accidents (two patients), coronary artery disease (two patients), congestive heart failure (two patients), and acute myocardial infarction (three patients). The authors concluded that LESU added to APL was better than APL alone at reducing SUA levels. It would be logical to suggest this should also result in better clinical outcomes, but the study was perhaps too short to demonstrate this.

Table 3 Summary of treatment-emergent adverse events with LESU

\begin{tabular}{|c|c|c|c|c|c|c|}
\hline \multirow[t]{2}{*}{ Adverse event } & \multicolumn{3}{|l|}{ CLEAR I ${ }^{13}$} & \multicolumn{3}{|l|}{ CRYSTAL ${ }^{15}$} \\
\hline & $\begin{array}{l}\text { APL } \\
\text { monotherapy } \\
\mathrm{N}=20 \text { I }\end{array}$ & $\begin{array}{l}\text { LESU200 + } \\
\text { APL } \\
\mathbf{N}=\mathbf{2 0 1}\end{array}$ & $\begin{array}{l}\text { LESU } 400+ \\
\text { APL } \\
\mathbf{N}=\mathbf{2 0 I}\end{array}$ & $\begin{array}{l}\text { PBO + FBX } \\
N=109\end{array}$ & $\begin{array}{l}\text { LESU200+ } \\
\text { FBX } \\
\mathrm{N}=106\end{array}$ & $\begin{array}{l}\text { LESU } 400+ \\
\text { FBX } \\
\mathbf{N}=109\end{array}$ \\
\hline Any TEAE, \% & 69 & 73 & 78 & 74 & 82 & 83 \\
\hline Any TEAE with RCTC toxicity grade 3 or $4, \%$ & 6 & 11 & 14 & 12 & 10 & 10 \\
\hline Any serious TEAE, $\%$ & 6 & 5 & 8 & 9 & 6 & 8 \\
\hline Any renal-related TEAE, \% & 4 & 4 & 10 & 6 & 9 & 10 \\
\hline Any TEAE leading to discontinuation, $\%$ & 4 & 8 & 7 & 8 & 9 & 14 \\
\hline
\end{tabular}

Abbreviations: APL, allopurinol; FBX, feboxustat; LESU, lesinurad; LESU200, lesinurad 200 mg; LESU400, lesinurad 400; PBO, placebo; RCTC, Rheumatology Common Toxicity Criteria; TEAE, treatment-emergent adverse event. 


\section{LESU in combination with FBX}

The initial study was a Phase Ib, multicenter, open-label, multiple-dose study of gout patients with high SUA ( $>8 \mathrm{mg} / \mathrm{dL}$ ) following cessation of urate lowering therapy. ${ }^{14}$ The aim of this study was to evaluate the pharmacodynamics, pharmacokinetics, and safety of LESU in combination with FBX. FBX 40 or $80 \mathrm{mg} / \mathrm{d}$ was administered on days $1-21$, LESU $400 \mathrm{mg} / \mathrm{d}$ was added on days 8-14, and then LESU was increased to $600 \mathrm{mg} / \mathrm{d}$ on days 15-21. SUA, urine uric acid, and pharmacokinetic profiles were evaluated at the end of each week. Initial FBX monotherapy resulted in one-half to two-thirds of subjects achieving an SUA level $<6 \mathrm{mg} / \mathrm{dL}$. FBX plus LESU 400 or $600 \mathrm{mg} / \mathrm{d}$ resulted in virtually all patients achieving a level under $5 \mathrm{mg} / \mathrm{dL}$. No clinically relevant changes in drug pharmacokinetics were observed. However, LESU did increase feboxustat concentrations by a small $\%$ and decreased colchicine levels by $20 \%$. An increase in creatine kinase levels was observed. Safety was similar to the other trials. The authors concluded that the clinically important targets of SUA are achievable in $100 \%$ of patients with combination therapy.

This was then followed by the CRYSTAL study ${ }^{15}$ which aimed to evaluate the efficacy and safety of LESU in combination with FBX in patients with tophaceous gout in a 12-month, Phase III trial. We included patients with high SUA ( $\geq 8.0 \mathrm{mg} / \mathrm{dL}$ or $\geq 6.0 \mathrm{mg} / \mathrm{dL}$ on preexisting urate-lowering therapy) and at least one tophus who were given FBX $80 \mathrm{mg}$ daily for a run-in period 4 weeks before randomization to LESU (200 or $400 \mathrm{mg}$ daily) or PBO in combination with FBX. The primary endpoint was the proportion of patients achieving SUA $<5.0 \mathrm{mg} / \mathrm{dL}$ at 6 months, while other endpoints measured tophus size and resolution at 12 months. Patients $(\mathrm{N}=324)$ were predominately male with a mean age of 54.1 years. Significantly more patients achieved SUA target levels with the combination of FBX and LESU $400 \mathrm{mg}(76.1 \%$; $p<0.0001)$, but not $200 \mathrm{mg}(56.6 \%$; $p=0.13$ ), versus FBX alone (46.8\%). With the exception of the primary timepoint, more patients in the LESU $200 \mathrm{mg}$ group achieved the SUA target. Complete tophus resolution was not different between groups (but this was an ambitious target within the study timeframe). However, LESU (200 $\mathrm{mg}$ and $400 \mathrm{mg}$ ) plus FBX reduced total target tophi area versus FBX monotherapy (50.1\% and $52.9 \%$ versus $28.3 \%$, respectively, $p<0.05$ ). Safety was generally comparable with FBX alone, except for higher rates of predominately reversible serum creatinine elevation, particularly with LESU $400 \mathrm{mg}$ (Table 3). The most common adverse events were nasopharyngitis, hypertension, headache, and extremity and back pain. The authors concluded that LESU in combination with FBX demonstrated superior SUA lowering compared with FBX alone with a clinically relevant effect on tophi in patients with tophaceous gout warranting additional therapy. Results with the larger trial appeared to not be as beneficial as the earlier phase trial.

In summary, LESU in combination with either APL or FBX is more effective than either agent as monotherapy in well-conducted multicenter trials. There is clear evidence of a dose response for both efficacy and toxicity. The combinations did not resolve tophi within the study timeframes but did decrease tophus area. Both the 200 and $400 \mathrm{mg}$ dose have been approved. LESU can be used with an eGFR as low as $30 \mathrm{~mL} / \mathrm{min}$ with no apparent change in efficacy. No data is available in any trials in patients with eGFR under $30 \mathrm{~mL} / \mathrm{min}$, so use in this group should not be considered at this point in time until more data becomes available. LESU-induced renal impairment is generally mild and often transient, but is common especially at the $400 \mathrm{mg}$ dose. This is thought to be due to urate deposition in the kidney. This should be carefully monitored until longer term studies become available. Similarly, an increase in creatinine kinase is also not uncommon. The mechanism is unclear but may be due to an interaction with or alterations in colchicine metabolism (as this was given as prophylaxis in most of these trials). This usually did not cause symptoms but should be monitored.

\section{Place in therapy}

This review indicates that there are a number of ways to approach patients who do not achieve a target SUA with APL monotherapy. These include higher doses of APL up to $600-800 \mathrm{mg} / \mathrm{d}$, switching to FBX, or using a xanthine oxidase inhibitor in combination with a uricosuric agent. All appear similar in terms of success rates, so which option to use comes down to physician and patient choice, cost, experience, and strength of the evidence base. The strongest evidence for the uricosuric combination option is available for LESU as trials of other agents are either nonexistent or based on small single-centre trials or the medicine is not available in major markets. These authors partly agree with the European League against Rheumatism guidelines, but suggest these should be expanded to consider all evidence-based options in the not-uncommon event of APL inadequate response.

\section{Disclosure}

GJ was an investigator on the CRYSTAL trial of lesinurad, and his institution was paid to perform this trial. The authors report no other conflicts of interest in this work. 


\section{References}

1. Hui M, Carr A, Cameron S, et al. The British Society for Rheumatology Guideline for the Management of Gout. Rheumatology. 2017;56: e1-e20.

2. Reginato AM, Mount DB, Yang I, Choi HK. The genetics of hyperuricaemia and gout. Nat Rev Rheumatol. 2012;8:610-621.

3. De Vera MA, Marcotte G, Rai S, et al. Medication adherence in gout: a systematic review. Arthritis Care Res. 2014;66:1551-1559.

4. Khanna D, Fitzgerald JD, Khanna PP, et al. 2012 American College of Rheumatology Systematic Guidelines for Management of Gout. Part 1: Nonpharmacologic and pharmacologic therapeutic approaches to hyperuricemia. Arthritis Care Res. 2012;64:1431-1446.

5. Richette P, Doherty M, Pascual E, et al. 2016 updated EULAR evidencebased recommendations for the management of gout. Ann Rheum Dis. 2017;76:29-42.

6. Stamp LK, O'Donnell JL, Zhang M, et al. Using allopurinol above the dose based on creatinine clearance is effective and safe in patients with chronic gout, including those with renal impairment. Arthritis Rheum. 2011;63:412-421.

7. Reinders MK, Haagsma C, Jansen TL, et al. A randomised controlled trial on the efficacy and tolerability with dose escalation of allopurinol $300-600 \mathrm{mg}$ /day versus benzbromarone $100-200 \mathrm{mg}$ /day in patients with gout. Ann Rheum Dis. 2009;68:892-897.

8. Dalbeth N, Stamp LK. Xanthine oxidase inhibitor treatment of hyperuricemia. In R. Terkeltaub, editor. Gout \& Other Crystal Arthropathies. Philadelphia: Elsevier; 2012:154-173.
9. Kannangara DRW, Graham GG, Wright DFB, et al. Individualising the dose of allopurinol in patients with gout. Br J Clin Pharmacol. 2017; 83(9):2015-2026.

10. Seth R, Kydd AS, Buchbinder R, Bombardier C, Edwards CJ. Allopurinol for chronic gout. Cochrane Database Syst Rev. 2014;(10): CD006077.

11. Reinders MK, van Roon EN, Jansen TL, et al. Efficacy and tolerability of urate-lowering drugs in gout: a randomised controlled trial of benzbromarone versus probenecid after failure of allopurinol. Ann Rheum Dis. 2009;68:51-56.

12. Perez-Ruiz F, Sundy JS, Miner JN, Cravets M, Storgard C; RDEA594203 Study Group. Lesinurad in combination with allopurinol: results of a phase 2, randomised, double-blind study in patients with gout with an inadequate response to allopurinol. Ann Rheum Dis. 2016; 75:1074-1080.

13. Saag K, FitzPatrick D, Kopicko J, et al. Lesinurad combined with allopurinol: A randomized, double-blind, placebo-controlled study in gout patients with an inadequate response to standard-of-care allopurinol (a US-Based Study). Arthritis Rheum. 2017;69:203-212.

14. Fleischmann R, Kerr B, Yeh LT, et al. Pharmacodynamic, pharmacokinetic and tolerability evaluation of concomitant administration of lesinurad and febuxostat in gout patients with hyperuricaemia. Rheumatology (Oxford). 2014;53:2167-2174.

15. Dalbeth N, Jones G, Terkeltaub R, et al. Lesinurad, a selective uric acid reabsorption inhibitor, in combination with febuxostat in patients with tophaceous gout: A Phase III Clinical Trial. Arthritis Rheum. 2017; 69(9):1903-1913
Drug Design, Development and Therapy

\section{Publish your work in this journal}

Drug Design, Development and Therapy is an international, peerreviewed open-access journal that spans the spectrum of drug design and development through to clinical applications. Clinical outcomes, patient safety, and programs for the development and effective, safe, and sustained use of medicines are the features of the journal, which

\section{Dovepress}

has also been accepted for indexing on PubMed Central. The manuscript management system is completely online and includes a very quick and fair peer-review system, which is all easy to use. Visit http://www.dovepress.com/testimonials.php to read real quotes from published authors.

Submit your manuscript here: http://www.dovepress.com/drug-design-development-and-therapy-journal 